\title{
Dynamics of High Energy Runaway Electrons in the Oak Ridge Tokamak
}

\author{
S. J. Zweben \\ H. Knoepfel
}




\section{DISCLAIMER}

This report was prepared as an account of work sponsored by an agency of the United States Government. Neither the United States Government nor any agency Thereof, nor any of their employees, makes any warranty, express or implied, or assumes any legal liability or responsibility for the accuracy, completeness, or usefulness of any information, apparatus, product, or process disclosed, or represents that its use would not infringe privately owned rights. Reference herein to any specific commercial product, process, or service by trade name, trademark, manufacturer, or otherwise does not necessarily constitute or imply its endorsement, recommendation, or favoring by the United States Government or any agency thereof. The views and opinions of authors expressed herein do not necessarily state or reflect those of the United States Government or any agency thereof. 


\section{DISCLAIMER}

Portions of this document may be illegible in electronic image products. Images are produced from the best available original document. 


\section{Printed in the United States of America. Available from National Technical Information Service \\ U.S. Department of Commerce 5285 Port Royal Road, Springfield, Virginia 22161 \\ Price: Printed Copy $\$ 4.50$; Microfiche $\$ 3.00$}

This report was prepared as an account of work sponsored by an agency of the United States Government. Neither the United States Government nor any agency thereof, nor any of their employees, contractors, subcontractors, or their employees, makes any warranty, express or implied, nor assumes any legal liability or responsibility for any third party's use or the results of such use of any information, apparatus, product or process disclosed in this report, nor represents that its use by such third party would not infringe privately owned rights. 
Contract No. W-7405-eng-26

FUSION ENERGY DIVISION

DYNAMICS OF HIGH ENERGY RUNAWAY ELECTRONS

IN THE OAK RIDGE TOKAMAK

S. J. Zweben

Oak Ridge Associated Universites

Graduate Participant

and

H. Knoepfel

On leave from Centro Gas Ionizzati

Frascati, Italy

Date Published - December 1977

This report was prepared as an account of work sponsored by the United States $C$ United States nor the United States Department of Energy, nor any of their employees, nor any of their contractors, subcontractors, or their employees, makes any warranty, express or implied, or assumes any legal hability or responsibility for the aceuracy, completeness or usetulness of any information, apparatus, product or process disclosed, or represents that its use would not infringe privately owned rights.

NOTICE This document contains information of a preliminary nature. It is subject to revision or correction and therefore does not represent a final report.

Prepared by the OAK RIDGE NATIONAL LABORATORY Qak Ridge, Tennessee 37830 operated by UNION CARBIDE CORPORATION

for the DEPARTMENT OF ENERGY 


\section{DYNAMICS OF HIGH ENERGY RUNAWAY ELECTRONS}

IN THE OAK RIDGE TOKAMAK

H. Knoepfe1 ${ }^{*}$ and S. J. Zweben ${ }^{\dagger}$

Oak Ridge National Laboratory

Oak Ridge, Tennessee 37830

\section{ABSTRACT}

Runaway electrons produced during normal discharges in the Oak Ridge Tokamak (ORMAK) have been studied with a hard $\mathrm{x}$-ray diagnostic system along with most of the other diagnostics available on this machine. It is found that runaways can attain maximum energies of up to $10 \mathrm{MeV}$ and be contained over times of typically 50 msec. A simple physical model is proposed that is consistent with most of the observed high energy runaway phenomena. Some properties of the overall runaway distribution generated in tokamaks are inferred from these results and are discussed in terms of runaway generation, acceleration, and transport.

\section{INTRODUCTION}

Runaway electrons keep appearing, under various discharge conditions, in most toroidal plasma devices.1,2 This is not surprising, since the formation of runaway electrons is a fundamental physical effect that is intimately related to the conduction of current in an ionized gas. 3

It is the purpose of this work to show, on the basis of some selected experimental results obtained during an extensive study of runaway phenomena in ORMAK, ${ }^{4}$ that in some normal discharges:

1) An appreciable number of electrons can attain energies up to $10 \mathrm{MeV}$.

2) These runaways can be accelerated in the electric field of the discharge as (nearly) free electrons and are contained over times of cypically $50 \mathrm{msec}$.

3) Most of the confinement effects can be ordered and understood in terms of a simple drift orbit model. 
On the basis of these results, some properties of the overall runaway distribution generated in tokamaks are then inferred and discussed in terms of runaway generation, acceleration, and transport.

A practical consequence of these findings - pointing towards the use of these high energy runaways as a means to probe the plasma - is that whenever runaway electrons do not perform according to the drift orbit model, specific physical effects should exist in the discharge that alter their production rate, reduce their containment, or augment their friction in the plasma. Although some of these anomalous effects will he mentinned, in general this work is concerned with the runaway behavior in normal discharges in the absence of gross instability of the plasma or runaway components. In this case the high energy runaway behavior is generally consistent with the drift orbit model described in Sec. II.

The data reported in the following sections have been obtained from most of the standard diagnostic systems avallable on ORMAK; of particular relevance is the hard $\mathrm{x}$-ray detection system that was developed for this study. 5 It is made up of two well collimated and shielded NaI ( $\mathrm{Tl}^{*}$ ) scintillation detectors which look tangentially at the limiter and/or at other targets in the discharge chamber (Fig. 1); they allow a time- and space-resolved measurement of the bremsstrahlung energy and intensity spectrum. In addition, there are two other scintillation detectors and an ionization chamber located at various places around the machine to monitor the hard $x$-ray intensity. The scintillation data are stored and analyzed by hardware and software that are integrated into the ORMAK data analys is system.

II. DRIFT ORBIT MODEL

The experiments show that in ideal discharge conditions the high energy runaways behave basically as freely accelerated electrons. The trajectory of a free electron with kinetic energy $\mathrm{T}=\mathrm{mc}^{2}(\gamma-1)$ in a tokamak configuration consists of a fast gyration at the (toroidal, $B_{T}$ ) magnetic field Larmor frequency,

$$
\Omega_{T}=\frac{e B_{T}}{\gamma m_{0} c},
$$


about a guiding center whose path lies on a drift surface. This drift surface is the result of movement along the helical field lines and of the (vertical) drift with velocity

$$
v_{d}=\frac{1}{R_{0} \Omega_{T}}\left(v_{\|}^{2}+\frac{1}{2} v_{1}^{2}\right)
$$

where $R$ is the distance of the particle from the major axis. For runaway electrons $\left(v_{\|} \gg v_{1}\right)$, the velocity is normally determined principally by the curvature drift, $v_{d} \simeq\left(v_{\|}\right)^{2} /\left(R \Omega_{T}\right)$. The projection of the helical movement onto a cross-sectional plane gives a circular movement with velocity $v_{h}=v_{\|} \frac{B_{P}}{B_{T}}$, where $B_{P}$ is the poloidal field due to the plasma. current. The combination of the $v_{d}$ and $v_{h}$ movements results in a projected trajectory that is approximately a circle shifted outward by the distance $d_{\gamma}$ from the center of the current distribution (Fig. 1).

The conservation of canonical angular momentum,

$$
P_{\phi}=\gamma m_{i} \operatorname{Rv}_{\|}-(e / c) \psi(r)
$$

in a steady-state condition can be used to calculate $d_{\gamma}$. For example, for a filamentary current (i.e., all current I flows within the runaway drift surface) the poloidal flux function is

$$
\psi=\int_{0}^{\mathrm{r}} \mathrm{B}_{\mathrm{P}} \mathrm{Rdr}=\mathrm{R}_{\mathrm{o}}(\mathrm{I} / \mathrm{c})[1+2 \ln (\mathrm{r} / \mathrm{a})] .
$$

Equating $P_{\phi}$ at point $A$ (see Fig. 1 , where $R \equiv R_{0}-r_{c}+d_{\gamma}, r \equiv r_{c}-d_{\gamma}$ ) and point $B\left(R \equiv R_{0}+r_{c}+d_{\gamma}, r \equiv r_{c}+d_{\gamma}\right)$ gives finally

$$
d_{\gamma} \simeq \frac{r_{c}^{2}}{2 R} \frac{I_{A}}{I}
$$

where

$$
I_{A}=\beta \gamma \frac{m_{0} c^{2}}{e}=17 \sqrt{\gamma^{2}-I}
$$

is the Alfvén current (in kiloamperes). 
Other more realistic current profiles can be handled with the same method or can be determined numerically. For example, the insert of Fig. 2 shows some shifted orbits that just intersect the limiter in a typical ORMAK type $B$ current profile,

$$
j(r)=j_{0}\left[1-\left(r / r_{L}\right)^{3}\right]
$$

Experimentally, the runaway is detected through the bremsstrahlung produced when its orbit intersects the target (outer limiter) at a radius $r_{L}$. That occurs when $r_{c}+d_{\gamma}+d_{p}=r_{L}$, for example for a filamentary current profile when

$$
\frac{I_{A}}{I} \simeq \frac{2 R_{U}}{r_{c}}\left[\frac{r_{L}}{r_{c}}-1-\frac{\dot{d}_{p}}{r_{c}}\right] \text {, }
$$

where $d_{p}$ is the shift of the current distribution as measured by magnetic Loops. ${ }^{\mathrm{p}}$ It can be shown? that for orbits with large radii the mean radius $r_{c}$ at intersection (Fig. 1) is approximately identical with the radius of the magnetic surface on which the runaway started off before acceleration.

Equation (8) thus provides the relation between the unknown initial orbit radius $r_{c}$ and the measurable kinetic energy of the electron when it finally hits the outer limiter. This intersection condition is plotted in Fig. 2, with similar curves relative to other current distributions.

This model may be extended.to give further relations between measurable quantities and therefore to provide additional information on the runaway process. For example, the number of runaways $\Delta s_{R}$ driven into the limiter per unit time as a consequence of the orbit shift with $d_{p}$ constant is given by

$$
\frac{\Delta \mathrm{S}_{\mathrm{R}}}{\Delta \mathrm{t}}=4 \pi^{2} \mathrm{R} \mathrm{r}_{\mathrm{c}} \mathrm{n}_{\mathrm{R}} \frac{\Delta \mathrm{d} \gamma}{\Delta \mathrm{t}}
$$

The velocity $\Delta d_{\gamma} / \Delta t$ with which the drift surfaces shift into the limiter can be calculated from Eq. (8) or Fig. 2 with the energy $[\gamma=\gamma(t)]$ and the current $[I=I(t)]$ both being measurable quantities. Since $S_{R}=S_{R}(t)$ can also be measured, it is thus possible to determine, within the 
assumptions and precision of this method, the initial local runaway density $n_{R}=n_{R}\left(r_{c i}\right) .8$ However, with the limited precision of present experimental data, the results of such deductions are somewhat open to discussion.

The acceleration of runaway electrons can be described by considering an approximate model in which free electrons are accelerated from time $t_{0}$ by the electric field $E_{\phi}$ along the toroidal direction $\phi\left(v_{\phi}=v_{\|}\right)$. The equation of motion is

$$
\frac{d\left(\gamma m_{0} v_{\phi}\right)}{d t}=-e E_{\phi}
$$

or

$$
\frac{d \sqrt{\gamma^{2}-1}}{d t}=\frac{e}{m_{0} c} \frac{d A_{\phi}}{d t} \text {. }
$$

Here $A_{\phi}$ is the only component of the vector potential in this axisymmetric problem and is given by

$$
A_{\phi}\left(r_{R}, t\right)=\int_{t_{0}}^{t} \frac{V_{L}(t)}{2 \pi R} d t-F\left(r_{R}, t\right),
$$

where $V_{L}$ is the measurable loop voltage (along the toroidal discharge vesse1) and $F\left(r_{R}, t\right)$ is an inductive correction term ${ }^{g}$. that is roughly proportional to $\mathrm{dI} / \mathrm{dt}$ and is thus generally negligible except during the initial breakdown phase. Integration of Eq. (10) is straightforward, and for the kinetic energy $T$ of the runaway we thus obtain

$$
\frac{T}{m_{0} c^{2}}=\gamma-1=\sqrt{1+\left(\frac{e}{m_{0} c^{2}} A_{\phi}\right)^{2}}-1 .
$$

\section{RUNAWAY ENERGY}

High energy runaway electrons in ORMAK discharges can be lost to the limiter either
1) at the very beginning,
2) during the current plateau phase, or
3) when the current decays, as documented in Fig. 3. 
In many cases, the runaway loss to the limiter is smooth and steady and can be described with surprising accuracy with the drift orbit model. In other cases, characterized by a noticeable MHD activity in the discharge, runaway losses to the limiter are somewhat enhanced and are in phase with the MHD surface effects: Strong disruptive instabilities may also dump most or even all of the runaways in the discharge.

Energy spectra of runaway electrons have been studied for different discharge types and different intervals within one discharge. Instead of following the direct double unfolding procedure necessary to determine the electron energy distribution from the scintillation pulse helght spectrum, we assume some discrete electron energies and compare the resulting scintillation spectra with the experimental ones. ${ }^{5}$ The results given in Fig. 4 show that substantial $10 \mathrm{MeV}$ runaway components exist in such discharges. It is also apparent that because the highest energy runaways produce copious bremsstrahlung quanta over the whole spectrum, it is nearly impossible under these circumstances to obtain any useful information relative to the lower energy ( $\leqslant 2-\mathrm{MeV})$ electrons.

For normal ORMAK discharges, there are two distinct patterns of runaway loss associated with different density regimes. For the high density case $\left(\bar{n}_{e} \geq 2 \times 10^{13} \mathrm{~cm}^{-3}\right.$ at $\left.\approx 100 \mathrm{kA}\right)$, the only runaway loss occurs during the current rise phase. For the low density case $\left(\bar{n}_{e}<2\right.$ $\times 10^{13} \mathrm{~cm}^{-3}$ at $\approx 100 \mathrm{kA}$ ), the main loss occurs during the steady-state and decay phases. (For the intermediate density case, both patterns can occur in the same discharge.) In either case, however, the maximum energy is seen to increase in time to nearly $10 \mathrm{MeV}$, over a period of $\$ 10 \mathrm{msec}$ during the initially high loop voltage or over a period of $\lesssim 50 \mathrm{msec}$ during the lower voltage in the steady state.

The knowledge of the maximum energy of the runaways on impact with the limiter can, through use of the model described in Sec. II, provide useful information concerning the radial distribution and acceleration of this group of runaways. The relevant maximum energy is deduced from the high energy end of the measured $x$-ray spectrum through a procedure similar to that shown in Fig. 4.10 
A. Runaways lost at early times

A straightforward and interesting experimental result based on this simple but effective diagnostic method is shown in Fig. 5. The evolution of the maximum energy at early times is compared with free-fall curves; this shows that the corresponding electrons must have been generated at $t_{R} \simeq 0.4 \pm 0.4 \mathrm{msec}$, at a time when the discharge is still cold $(1-5 \mathrm{eV})$ and only partially ionized. They are then accelerated nearly as free electrons in the applied loop voltage $v_{L}$ of $3-40 \mathrm{~V}$ per turn (Fig. 3). The mean line-averaged electron density at full ionization is relatively high in these shots; $\overrightarrow{\mathrm{n}}_{\mathrm{e}}=2.5-3.5 \times 10^{13} \mathrm{~cm}^{-3}$ at $5 \mathrm{msec}$. It is therefore no surprise that the overall number of high energy runaways is relatively sma11, typically $\mathrm{N}_{\mathrm{R}}=10^{12}$ electrons or a $10-\mathrm{A}$ circulating current. An analysis of the orbits of these electrons through Eq. (8) shows that their minor radii are in the range $r_{c}=17-19 \mathrm{~cm}$ when intersecting the outer limiter. This result suggests the existence of a skin effect for electric field penetration (see Sec. V). It is also possible that in these discharges, characterized by a moderate MHD activity at early times, runaways are transported.somewhat by ergodic wandering of the field lines. This effect is small enough, however, to allow nearly perfect confinement of runaways over the whole current rise phase.

It should be noted that in this series of experiments, the discharge is leaning towards the inside limiter, leaving space for shifted high energy electron orbits of large radius to remain contained. As a matter of fact, if the discharge in this early phase were leaning towards the outside limiter, as is typical of most ORMAK discharges, the energy of the same runaways at collision with the limiter would have been only 50-100 keV:

It is most 1ikely that runaway formation during breakdown is not limited only to those documented ORMAK discharges, but is typical of most tokamak operations. For reasons just mentioned, peripheral runaways will, however, be mostly lost to the limiter or the wall before gaining relativistic energies. This effect has qualitatively been confirmed by pulses of soft and medium $x$ ray that have been detected at these early times whenever we looked for them. 
B. Runaways lost during steady state

For discharges with mean electron densities $\left(\bar{n}_{e}\right)$ of $0.5-2.0 \times 10^{13}$ $\mathrm{cm}^{-3}$, large numbers of runaway electrons are generated after $t \simeq 5 \mathrm{msec}$ and accelerated to high energies. They then gradually drift into the limiter from about mid-discharge on, with particularly large numbers being lost during current decay.

Maximum energy is plotted vs time for two sets of discharges in Fig. 6; the points have basically the same meaning as in Fig. 5. Since the electrons in Fig. 6 are accelerated more slowly during this phase of the discharge and are contained longer, the interpretation of their confinement is more open to discussion.

The points along curve (a) in Fig. 6 follow the free-fall slope within $90 \% \pm 10 \%$ in such a way that if free fall is assumed also for $\mathrm{E}<5 \mathrm{MeV}$ their birthtimes would be $\approx 10 \mathrm{msec}$. The radii of the measured runaways along this curve as computed from the orbit model range from 16 to $19 \mathrm{~cm}$. Along with an estimate of the absolute runaway 1oss, as shown at the bottom of the figure, this gives a local density of $\approx 10^{7} \mathrm{~cm}^{-3}$ for these runaways.

Although such near-free-fall behavior has been seen in most cases, the energy gain can sometimes be smaller, as shown, for example, by curve (b). Here the energy gain is $60 \% \pm 10 \%$ of free fall. At present, there is no convincing explanation for this result, although the most likely causes are an anomalous friction or an enhanced radial diffusion rate. Note that a time- or radius-dependent friction cannot be ruled out for runaways below $5 \mathrm{MeV}$ in curve (a) and could place their birthtime anywhere between 0 and $10 \mathrm{msec}$.

C. Runaways lost at current decay

After the driving voltage ends, the discharge current starts decaying. As a consequence of the increased orbit shift [see Eq. (5)], all the runaways will eventually hit the limiter. The results plotted in Fig. 7 show that the energy and intensity can be consistently understood in terms of the drift orbit model. In particular, the strong increase of bremsstrahlung at the outer limiter when the current starts decaying is 
obtained because the current decay term in Eq. (5) is much larger than the inward plasma shift which occurs at this time (see Fig. 6). Note that the last runaways to be dumped have smaller radii and lower energies, as would be expected for runaways born later in the hot central core of the discharge. Note also that in the high current discharge described in Fig. 7, runaways are dumped relatively late in time. Generally, the higher current discharges show better runaway confinement during the steady state and also a larger dump during the later phases of the current decay. This behavior is consistent with the I/I scaling implied by the drift orbit model of confinement.

The total number of high energy runaways shown in Fig. 7 amounts to $10^{13}$ or an equivalent current of roughly $100 \mathrm{~A}$ for the sum of these maximum energy components. The uncertainty in this number, which is calculated on the basis of the absolute bremsstrahlung intensity, is a factor of three either way. In other similar shots the number can be substantially higher, depending on the plasma density (as discussed in Sec. V).

In ORMAK, the transformer providing the electromotive force (emf) is driven by a capacitor bank for the first $15 \mathrm{msec}$. When this time has elapsed, a lead cell battery is usually switched in to keep the discharge current at a constant level. In the series of experiments represented in Fig. 8, only the capacitor bank was used, and the capacitor voltage $V_{c}$ was varied to change the overall flux swing $\phi$ within the discharge vessel. Each point in the figure thus corresponds to the runaway behavior observed for a particular charging voltage. The measured maximum energies can be shown to follow the free-fall gain if the runaways are all started at $t_{0} \cong 3 \mathrm{msec}$, thus allowing them to miss a fraction of the flux swing. As before, the results leave some room open for speculation as to what happens to the maximum energy runaways before they become detectable, that is, below $2 \mathrm{MeV}$. For example, it is possible that electrons start near $t_{o}=0 \mathrm{msec}$ but their energy gain in the first few milliseconds of their lifetime is reduced by enhanced friction. It is clear, however, that the late dump (and thus the small calculated orbit radii) of these runaways distinguishes them from the group of breakdown runaways obtained at higher densities (see. Ser. J.II.A). 
We note two interesting features of this result with respect to runaway production. First, for the group of discharges at $0.09 \mathrm{~Wb}$ in Fig. 8, the preionization pulse amplitude was varied appreciably with apparently no systematic effect on either the maximum energy or intensity of the high energy runaways. Second, the number of high energy runaways is seen to decrease with increased voltage. This unexpected behavior (see Sec. V) is due to the dependence of $\mathrm{n}_{e}$ (and probably $\mathrm{T}_{e}$ ) on the applied voltage (see Fig. 8) and points out the difficulty of predicting runaway production in tokamak discharges.

Finally, it may be interesting to note that in an additional series of experiments the flux swing range was further extended up to $0.8 \mathrm{~Wb}$ by switching the battery into the transformer clrcuit for various lengths of time. In these experiments the maximum energy of runaways dumped at the end of the discharges increased at only one third the rate expected from free fall in the extra flux swing. No clear-cut explanation can be given for this effect. It is possible, though, that the runaways did continue in free fall, but their population was not detectable in the presence of a large number of runaways born later.

\section{RUNAWAY TRANSPORT}

\section{A. Overall transport properties}

Runaway electrons become relativistic after they have passed through several initial phases in their lifetime. Three major phases can be defined by critical energy ranges. The first concerns the runaway birth and can be defined by $T<W_{1}$, where typically $W_{1} \simeq 2 e e_{c} c / \nu_{e i}$ is on the order of the critical runaway energy, implying that at $W_{1}$ the runaway becomes decoupled from the plasma. Here $\nu_{e i}$ is the collision frequency and $E_{c}$ is given in Eq. (14); thus for a normally hot plasma ( $n_{e}=3$ $\times 10^{13} \mathrm{~cm}^{-3}, \mathrm{~T}_{\mathrm{e}}=1 \mathrm{keV}$ ), we obtain $\mathrm{W}_{1} \simeq 40 \mathrm{keV}$. In this phase, the generation of runaways and the friction experienced by recently born runaways may be mostly determined, in addition to Coulomb collisions, by collective interaction modes. This may result in a reduced number of runaways and in pitch angle scattered or slowed-down runaways on one hand 
and in emission of enhanced electron synchrotron and plasma radiation on the other. ${ }^{3,11}$ Correlation between runaway effects and enhanced high frequency radiation has been detected in many experiments ${ }^{12}$ and also in ORMAK. ${ }^{13}$ In this phase an enhanced transport of runaways may be related to the anomalously large electron energy loss characteristic of tokamak discharges.

The second phase may be defined by the kinetic energy interval $\left(W_{1}, W_{2}\right)$. Here $W_{2}$ is the energy at which the orbit shift $d_{\gamma}$ [Eq. (5)] typically becomes equal to the radial thickness $\Delta \mathbf{r}_{\mathrm{m}}$ of defects in the magnetic configuration (in ORMAK, at half radius with $\Delta \mathrm{r}_{\mathrm{m}} \simeq 1 \mathrm{~cm}$, we have $\left.\mathrm{W}_{2} \simeq 1 \mathrm{MeV}\right)$. In this phase, the drift velocity of runaway electrons along magnetic field lines is typically larger by a factor of 100 than that of the bulk of electrons carrying current; thus the runaway electrons sense dramatically any ergodicity of the magnetic topology. Relatively large runaway losses measured ${ }^{14}$ in smaller plasmas than ORMAK's could be due to this effect. Very small magnetic perturbations $\left(\tilde{B} / B \gtrsim 10^{-4}\right)$, which can be induced by experimentally observed drift waves $\left(\mathrm{e} \Phi / \mathrm{kT} \mathrm{e}^{\sim 10^{-2}}\right), 15$ can thus enhance very substantially radial transport of runaways in this energy range.

In addition, major defects in the smooth magnetic topology, such as islands along mode rational surfaces, internal sawtooth oscillations, or disruptions, can affect the radial transport of runaways much more than in the previous case. In fact, detailed correlation between such activities (measured by magnetic probes or by a positive-intrinsic-negative diode array sensitive to soft $x$ rays) and the hard $x$-ray signal at the limiter has repeatedly been measured. 10

Finally, for kinetic energies larger than $W_{2}$, the drift surfaces decouple partially from the magnetic flux surfaces, and the inertia of the electrons increases by the factor $\gamma$. The runaways are less affected by small-scale and resonant effects, and their confinement time can greatly exceed the electron energy containment time, as shown by our experiments. For example, in the discharges described in Secs. II.B and II.C, the high energy runaway containment time can exceed $50 \mathrm{msec}$, while the electron energy confinement time is typically $\$ 5 \mathrm{msec}$. 
B. Normal limiter-target effects

According to our model, under normal discharge conditions the high energy runaways move on orbits that are always shifted outward along the major radius with respect to the current distribution in the plasma. The intensity plot given in Fig. 9a indeed shows a strong bremsstrahlung source at the outer limiter and no clearly detectable source at the inner limiter. (The remaining intensity roughly corresponds to the estimated background of radiation that is Compton-scattered into the acceptance cone of the collimator.)

A confirmation of the basic loss mechanism was found during inspection of the ORMAK limiter after more than three years of operation, during which many series of runaway beam discharges were also sustained. The main damage pattern that might be ascribed to impact of high energy electrons is a slight melting at the outer limiter extending about $3 \mathrm{~cm}$ up and down from the equatorial symmetry plane, that is, just where the drifted and perfectly symmetric electron orbit should intersect the limiter.

The very good containment of these high energy runaways within the plasma makes it possible to shift their orbits in the machine along with the plasma by changing the vertical field. If the orbits are shifted inward (as, for example, in Fig. 5), the runaways are allowed to gain more energy before hitting the limiter. A series of such shift experiments ${ }^{10,13}$ as well as the simflar experiment documented in Fig. 5 substantially confirm.the drift orbit model. Recent experimental results show that in addition to the velocity $\Delta \mathrm{d}_{\gamma} / \Delta t$ with which the drift surfaces shift into the limiter. [for which from Eq. (9) a typical value is found to be $10^{2} \mathrm{~cm} / \mathrm{sec}$; , an additional (formal) diffusion process with $\mathrm{d} \approx 10^{2}$ $\mathrm{cm}^{2} / \mathrm{sec}$ can be allowed. This process increases somewhat the transport of high energy runaways near the outside of the discharge where, in fact, additional effects may play a role (see Sec. IV.A).

\section{Point limiter effects}

A further test of the validity of the drift orbit model was made with an experiment in which an additional movable limiter in the form of a 
1-cm-diam tungsten rod was radially pointed into the discharge chamber in the equatorial plane (see insert, Fig. 9b). As this limiter was gradually. inserted over a series of shots, the hard $x$-ray intensity at the outer section of the ordinary limiter, measured in the usual way, was found to decrease correspondingly (Fig. 9b); however, the intensity at the inner section of the limiter, lower by about a factor of 100 , remained roughly constant during such runs. The intensity at the outer limiter was seen to decrease gradually over an insertion distance of $\leqslant 2 \mathrm{~cm}$, as shown in Fig. 9b.

In addition, the movable limiter, upon removal after about 30 discharges, showed a damage pattern consistent with high energy electron impact (see insert, Fig. 9b). In particular, the flat surface facing the plasma was not damaged, as it would have been if the overall limiter damage were due to hot, normal conduction electrons or ions, or to runaways with a substantial radial velocity.

Both observations relative to the inserted movable limiter indicate that high energy runaways can move radially outward as much as $d_{d} \simeq 1.5 \mathrm{~cm}$ past the tip of this limiter. To estimate the corresponding radial. diffusion velocity $v_{r}$, we note that the ideal relativistic electron moving without transverse energy on an orbit with mean radius $r_{c}$ is likely to hit the tungsten rod with diameter $2 r_{t}$ only after $2 \pi r_{c} / 2 r_{t}$ toroidal transits, each of which is completed in the time $2 \pi R_{0} / c$; hence, $v_{r}=d_{d}\left(r_{t} / \pi r_{c}\right)\left(c / 2 \pi R_{o}\right)$, so with $r_{c} \cong 18 \mathrm{~cm}$, it follows that $v_{r} \simeq 400 \mathrm{~cm} / \mathrm{sec}$. It is obvious that this outward velocity could only be effective a short distance from the limiter, implying that this is a surface rather than a bulk phenomenon, because otherwise the mean lifetime of electrons would be much less than that required to gain relativistic energies.

There are several effects that can explain this enhanced diffusion. The most relevant with respect to the high energy runaway experiment reported in Fig. $9 \mathrm{~b}$ is a scattering of the electrons as they hit the point limiter. In fact, as the runaways (initially with small transverse momentum) move outward with the slow drift orbit motion discussed in Sec. IV.B, they should eventually hit the point limiter within less than a millimeter of its tip. In such a collision, there is a good chance that the electron is not absorbed but is instead violently scattered. In a 
plane tungsten target, for example, the backscattered fraction of normally incident $4-\mathrm{MeV}$ electrons can be as high as $30 \% .16$ Electrons hitting a cylindrical limiter can, in addition, be scattered by the curved surfaces and also through the flat surface facing the plasma; it is estimated that $20-30 \%$ of these electrons will be neariy elastically scattered away. from the limiter into gyro-orbits with a pitch angle of more than $20^{\circ}$. The main consequence of such collisions is that the orbit of the scattered electrons is displaced by a mean step corresponding to the Larmor radius [Eq. (1)] or more if the runaway becomes trapped (typically for scattering angles of more than $50^{\circ}$ ). On consequent passages they may hit the main limiter (with a chance of being detected and thus reported as in Fig. 9b), be scattered a second time, or be absorbed by the point limiter. This effect is somewhat difficult to express in exact quantitative terms, due to the complex geometry of the two targets, but since elastic scattering prevails so strongly over bremstrahlung radiated into the detector's high energy acceptance range, there remains an ample margin to cover the experimental observations. Notice that a similar scattering effect also exists with only the normal limiter in place; however, due to 1 ts large poloidal extension, the radial displacement of runaway impact will be somewhat less pronounced.

\section{RUNAWAY PRODUCTION}

In recent years, an appreciable amount of theoretical and numerical work on runaway production rates has been presented, generally based on ideal plasma models and on Coulomb collisions only. However, these results are so critically and strongly dependent on some plasma parameters, such as electron density $\mathrm{n}_{e}$ and temperature $\mathrm{T}_{e}$, and also on collective effects that have not been sufficiently taken into account, that at present.some doubts exist about their applicability to real plasmas.

For the relative rate $\mathrm{s} / \mathrm{n}_{\mathrm{e}}$ of electrons running away per second in a fully ionized plasma, we take here for comparison with the experiments the result of Kulsrud et $a 1.17$ and rewrite it in the approximate practical form 


$$
\frac{S}{n_{e}} \simeq 1.6 \times 10^{9} \frac{\left(n_{e} / 10^{13}\right)}{T_{e}^{3 / 2}}\left(\frac{E_{c}}{E}\right)^{0.375} \exp \left(-\frac{E_{c}}{4 E}-\sqrt{\frac{2 E_{c}}{E}}\right) .
$$

The characteristic runaway field

$$
E_{c}=4 \pi e^{3} \frac{\mathrm{n}_{e}}{\mathrm{kT}_{\mathrm{e}}} \ln \Lambda
$$

can be taken in the form (with $\ln \Lambda \simeq 15$ )

$$
E_{c} \simeq 4 \times 10^{-2}\left(\frac{n_{e}}{10^{13}}\right)\left(\frac{10^{3}}{T_{e}}\right)
$$

where $\mathrm{T}_{\mathrm{e}}$ is measured in $\mathrm{eV}, \mathrm{n}_{\mathrm{e}}$ in $\mathrm{cm}^{-3}, \mathrm{E}$ and $\mathrm{E}_{\mathrm{c}}$ in $\mathrm{V}-\mathrm{cm}^{-1}$.

There are at least three basic effects that modify the runaway rates in real plasmas with respect to what is given above. Probably the most general one is due to collective plasma modes (see Sec. IV.A).

The second effect concerns impurity ions in the plasma. According to an expression by Cohen, 18 in a typical ORMAK plasma $\left(E / E_{c} \leqslant 0.1\right)$ with effective ionic charge $z=6$ in the steady-state phase, the runaway rate would be smaller by an order of magnitude than given by Eq. (13). On the other hand, impurities are known to indirectly enhance runaway formation, particularly in the strong runaway type of discharge, where runaway beams are formed at early times; this has reproducibly been checked in ORMAK. ${ }^{9}$

Finally, there is an enhancement of runaway formation obtained during breakdown 19 in the partially ionized gas; this is due to the intermixed molecular gas, which provides a collisional (momentum transfer) cross section per molecule that is smaller 20 than twice the corresponding electron-ion cross section in the electron energy range up to about $50 \mathrm{eV}$. The very early breakdown runaways documented in Fig. 5 are most likely generated through this enhancement effect. In fact, unless one assumes a pronounced skin effect with.strong local heating, the high filling pressure and low initial temperature characterizing these discharges provide practically no detectable runaways through Eq. (13). 
On the basis of this expression and of measured $n_{e}, T_{e}$, and $E$ values, a typical evolution in time and radius of runaway generation rates in the ORMAK discharge is obtained in Fig. 10. It is clear that between the "early" and "steady-state" runaways there is a period from about 10 to $20 \mathrm{msec}$ during which runaway production is quenched because the electric field has decreased more than the temperature has increased. Another result is that at an early time ( $\leqslant 5 \mathrm{msec}$ ), as long as inductive effects reduce the electric field inside the discharge, runaway production may be higher at outer radii than in the center. With respect to runaways generated after this time, Fig. 12 shows a drastic increase in runaway intensity as the mean electron density (measured at $30 \mathrm{msec}$ ) becomes smaller than about $1.3 \times 10^{13} \mathrm{~cm}^{-3}$. The comparison with the relative theoretical curve shows that the experimental results can roughly be understood in terms of the density dependence given by Eq. (13).

It is interesting to attempt a quantitative comparison between this calculated runaway production and the observed population of high energy runaways. It must be kept in mind, however, that our measurements refer only to the highest energy components lost to the limiter at any time, as shown, for example, in Figs. 6 and 7.

Because runaways with the largest energies are predominantly formed in ORMAK at early times, we can compare the observed population of $\approx 10-\mathrm{MeV}$ runaways lost during the current decay to the expected number born at the free-fall-extrapolated birthtime of $t \approx 10 \mathrm{msec}$. From Fig. 10 (corrected for ORMAK $Z=6$ ), we find an expected runaway production during this time for a typical volume of $\gtrsim 10^{5} \mathrm{~cm}^{3}$ to be $\gtrsim 10^{15}$ electrons. This can be compared to the observed population of $\approx 10^{13}$ electrons for this density (Fig. 11). Apparently, either the production rate is less than classical or some of the runaways are lost before they reach maximum energy, probably before becoming relativistic. It must be kept in mind, however, that the uncertainties involved are at least a factor of three either way for each figure.

In addition, a steady-state production rate is in part reflected in the loss of lower energy components during the end of the current decay as described in Sec. III.C. In the high current, high temperature discharge of Fig. 7, this component evidently implies a significant 
production rate in the steady state, but in this case an anomalous frictional force on earlier born runaways cannot be ruled out as an explanation for the relatively low energy.

In larger tokamaks, ${ }^{1,2}$ this latter type of runaway may strongly predominate due to the increased time of the discharge pulse. A steady state in the population of runaway electrons in a discharge would be the result of a balance between runaway generation and 1oss; in general, these processes can be inferred only indirectly from experimental results. An enhanced loss rate for low energy runaway components can produce a similar result. 21

VI. CONCLUSIONS

The experimental results presented and discussed in this work show that in a variety of normal ORMAK discharge's, runaway electrons can be accelerated as (nearly) free electrons up to maximum energies of $10 \mathrm{MeV}$. They thus pass through the lower energy range ( $\leqslant 0.5 \mathrm{MeV})$ where they are critically exposed to collective plasma modes and defects of the magnetic topology.

A variety of indirect observations suggest that the dynamics of these high energy runaways can basically be understood in terms of a simple physical model. In particular, the surprisingly good confinement (for times of over $50 \mathrm{msec}$. for the higher energy components) which exists in spite of the complex oscillating magnetic topology of tokamaks may be hypothesized as being due to the sizable shift of the drifted orbits away from the magnetic flux surfaces.

The group of high energy runaways can influence the physics and the macroscopic characteristics of tokamak discharges, particularly at early times. For example, the early enhanced runaway formation.should in most cases give rise to an unstable positive slope in the electron distribution which would tend to produce a wave spectrum. This wave spectrum would self-consistently determine further runaway production and acceleration. Also, due to the electron stimulated desorption, ${ }^{22}$ this early runaway dump might cause influx of neutral gas and thus help to determine the character of the discharge. High energy runaways also have several important 
practical consequences later in the discharge, such as the generation of large fluxes of penetrating hard $x$-rays that interfere with many diagnostic systems, the generation of neutrons by photoreactions in the limiter material and/or by Coulomb dissociation of deuterium in the plasma, and possibly the enhancement of high $z$ impurity influx due to runaway induced evaporation of the limiter. One of these effects, anticipated earlier ${ }^{4}$ on the basis of our results, has meanwhile been detected and studied in detail. 23

The study of high energy electrons has allowed us to identify several distinct groups of runaways that can be classified in accordance with the time and condition of birth. In this sense the runaway population, as inferred from high energy results, qualitatively agrees with the theoretical runaway rate, but quantitatively tends to be more than an order of magnitude smaller than calculated.

In conclusion, considering the physical complexity of runaway phenomena in tokamak discharges, it can be seen that high energy runaway effects are remarkably reproducible and controllable.

\section{ACKNOWLEDGMENTS}

This work benefited from substantial contributions received from all the members of the ORMAK group. We also want to thank specifically L. A. Berry and J. F. Clarke for their constant support of the runaway program, as well as H. H. Fleischmann, D. A. Spong, and D. W. Swain for many valuable discussions and contributions. One of us (H. Knoepfel) wants to acknowledge in addition the support received from the Commission of the European Countries and to thank R. Toschi of the Centro Gas Ionizzati for having made possible his stay in Oak Ridge.

This research is sponsored by the Energy Research and Development Administration under contract with Union Carbide Corporation. 


\section{REFERENCES}

$*$

On leave from Centro Gas Ionizzati (Associazione EURATOM-Comitato. Nazionale Energia Nucleare), Frascati, Italy.

+ Oak Ridge Associated Universities graduate participant from Corne11 University, Ithaca, New York.

1. D. Grove, V. Arunsalam; K. Bol, D. Boyd, N. Brentz, M. Brusati, S. Cohen, D. Dimock, F. Dylla, D. Eames, H. Eubank, B. Fraenke1, J. Girard, R. Hawryluk, E. Hinnov, R. Horton, J. Hosea, H. Hsuan, D. Ignat, F. Jobes, D. Johnson, E. Mazzucato, E. Meservey, N. Sauthoff, J. Schive11, G. Schmidt, R. Smith, F. Stauffer, W. Stodiek, J. Strachan, S. Suckerwer, S. von Goeler, and K. Young, paper CN-35/A2 in Proc. 6th Conf: on P1asma Physics and Controlled Nuclear Fusion Research (1976).

2. A. B. Berlizov, C. A. Bobrovskii, A. A. Bagdasarov, N. L. Vasin, A. N. Vertiporokh, V. P. Vinogradov, N. D. Vinogradova, N. M. Gegechkory, E. P. Gorbunov, Yu. N. Dnestrovskii, V. S. Zaverjaev, A. B. Izvozchikov, S. Yu. Luk'anov, S. E. Lysenko, Yu. S. Maximov, G. E. Notkin, M. P. Petrov, G. N. Popkov, K. A. Razumova, V. S. Strelkov, and D. A. Shcheglov, paper CN-35/AI, in Proc: 6th Conf. on Plasmà Physics and Controlled Nuclear Fusion Research (1976).

3. B. Coppi, F. Pegoraro, R. Pozzoli, and G. Rewoldt, Nucl. Fusion 16, 309 (1976).

4. H. Knoepfel and S. J. Zweben, Phys. Rev. Lett. 35, 1340 (1975).

5. H. Knoepfe1, T. Renk, and S. J, Zweben, ORNL/TM-5022, Oak Ridge National Laboratory, Oak Ridge, Tennessee (1975).

6. J. L. Anderson, R. S. Booth, R. J. Colchin, R. V. Miske11, and J. M. Bailey, Nuc1. Fusion 16, 629 (1976).

7. D. A. Spong and D. W. Swain, Bul1. Am. Phys. Soc. 22(2), 182 (1977).

8. H. Knoepfel, D. A. Spong, and S. J. Zweben, Proc. 7th European Conf. on Controlled Fusion and Plasma Physics, Vol. I, p. 3 (1975).

9. H. Knoepfel, D. A. Spong, and S. J. Zweben, Phys. Fluids 20, 511 (1.977.)

10. S. J. Zweben, Ph.D. dissertation, Cornell University, Ithaca, New York (1977). 
11. For example, in C. S. Liu and Y. Mok, Phys. Rev. Lett. 38, 162 (1977) ; K. Papadopoulas, I. Haber, J. Huba, P. Palmadesso, and N. Winsor, Bull. Am. Phys. Soc. 22(2), 184 (1977).

12. For example, in D. A. Boyd, F. J. Stauffer, and A. W. Trivelpiece, Phys. Rev. Lett. $\underline{37}, 98$ (1976).

13. S. J. Zweben, D. W. Swain, J. B. Wilgen, and H. H. Fleischmann, Bul1. Am. Phys. Suc. 22(2), 182 (1977).

14. J. D. Strachan, Nucl. Fusion 16, 345 (1976).

15. J. D. Callen, to be published.

16. P. J. Ebert, A. F. Lawson, and E. M. Lent, Phys. Rev. 138, 422 (1969).

17. R. M. Kulsrud, Y. C. Sun, N. K. Winsor, and H. A. Fallon, Phys. Rev, Lett, 31, 690 (1973).

18. R. H. Cohen, Phys. Fluids 19, 239 (1976).

19. R. Papoular, Nucl. Fusion 16, 37 (1973).

20. H. S. W. Massey and E. H. S. Burhop, Electronic and Ionic Impact Phenomena (Clarendon Press, Oxford, 1969), Vol. II.

21. S. von Goeler, W. Stodiek, N. Sauthoff, and H. Selberg, Proc. 3rd Int1. Symposium on Toroidal Plasma Confinement (1975), p. B25.

22. S. K. Erents and G. M. McCracken, J. Appl. Phys. 44, 3139 (1973).

23. J. D. Strachan, E. B. Meservey, W. Stodiek, R. A. Naumann, and F. Girshick, Nuc1. Fusion 17, 140 (1977). 
FIGURE CAPTIONS

Fig. 1. Schematic cross section through an ORMAK discharge, where $R_{0}=80 \mathrm{~cm}$ and $r_{L}=23 \mathrm{~cm}$. A runaway drift surface $A B$ is shown shifted outward $d_{Y}$ from a magnetic $f$ lux surface which is itself shifted $d_{p}$ inside the chamber axis.

Fig. 2. Outer limiter intersection condition as a function of total plasma current (I) and electron energy $\left(I_{A}\right)$. The "filament" current curve corresponds to Eq. (8), the "flat" curve to uniform current density, and the "type B" curve to the current distribution of Eq. (7). Insert shows calculated orbit with $100 \mathrm{kA}$ of "type B" current for $5-\mathrm{MeV}$ (outer) and 10-MeV (inner) electrons.

Fig. 3. Hard ( $20.5-\mathrm{MeV}) \mathrm{x}$-ray intensity signatures for different types of ORMAK discharges as monitored by an uncollimated NaI detector. In discharges of intermediate density both the early and late $x$-ray signals may appear in the same discharge.

Fig. 4. A typical scintillator pulse height spectrum matched with theoretical curves. The histogram represents data obtained during a $5 \mathrm{msec}$ interval summed over four similar discharges ( $90-95 \mathrm{msec}$ in Fig. 7). The solid curve is the expected spectrum for $0^{\circ}$ emission from $2 \times 10^{11} 10-\mathrm{MeV}$ electrons normally incident on tungsten. The broken curve includes an additional component of $4 \times 10^{11}$ electrons at $5 \mathrm{MeV}$.

Fig. 5. Early time evaluation of the maximum runaway energy in two sets of discharges. The curves represent free-fall energy gain from $t=0$ assuming an $\mathrm{L} \cong 0.5 . \mathrm{H}$ appropriate for electrons at approximately $\mathrm{r}_{\mathrm{c}} \geq 18 \mathrm{~cm}$. Plasma current and shift curves are given for the 90-kA case.

Fig. 6. Maximum energy vs time for runaways hitting the limiter during the steady state of two discharges. Plasma current, plasma shift, number of electrons lost, and typical orbit radii are shown for the (a) diechargc. 
Fig. 7. Maximum energy and intensity of runaways hitting the limiter during the discharge current decay. The number of runaways lost and the calculated orbit radii are computed for the energy components shown at the top of the figure.

Fig. 8. Maximum energy vs total flux swing for a series of discharges in which the capacitor charging voltage $V_{c}$ was varied. Also shown is the variation in plasma density and in the estimated number of high energy runaways during this sequence.

Fig. 9a. Relative bremsstrahlung intensity (number of pulses above a threshold of $2 \mathrm{MeV}$ ) measured by the collimated detector as it sweeps in the equatorial plane from the inner to the outer limiter. The FWHM of the collimator's acceptance cone measured at the limiter is $6 \mathrm{~cm}$.

Fig.'9b. Relative bremsstrahlung intensity measured at the outer limiter for various insertion distances of the point limiter. The melting of the point limiter is due to runaway impact.

Fig. 10. Runaway rate $\mathrm{S}$ for a pure hydrogen plasma calculated vs time and radius from measured density and temperature profiles in ORMAK. The electric field is calculated from the loop voltage, using $L=0.5 \mu \mathrm{H}$ for the outside $(r \cong 15 \mathrm{~cm})$ and $\mathrm{L}=0.9 \mu \mathrm{H}$ for the inside $(r \cong 0)$. Note that the steady-state rate is more commonly higher on axis due to a peaked temperature profile.

Fig. 11. Relative intensity of high energy ( $(2-\mathrm{MeV})$ runaways from three different experimental series vs mean electron line density. Solid line is obtained from Eq. (13) with $\mathrm{T}_{\mathrm{e}}=300 \mathrm{eV}$ and $\mathrm{E}=1 \times 10^{-3} \mathrm{~V} / \mathrm{cm}$ and is normalized at $\bar{n}_{\mathrm{e}}=1.2 \times 10^{13} \mathrm{~cm}^{-3}$ with the experimental points. Note that these data refer to runaways lost during the steady-state and current decay phases of the discharge, and so describe runaway production characteristic of $t \approx 5-15 \mathrm{msec}$. 


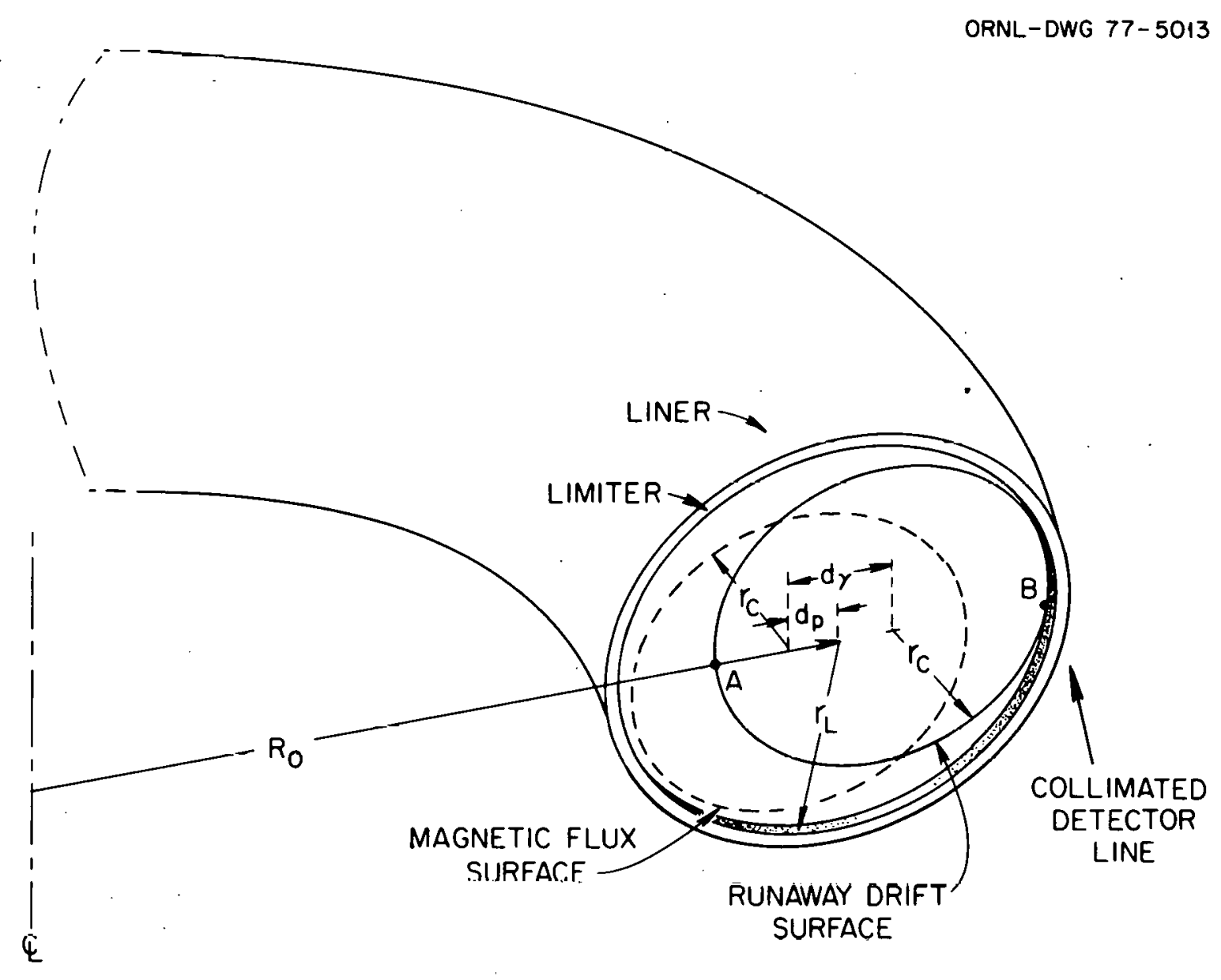

Fig. 1 . 


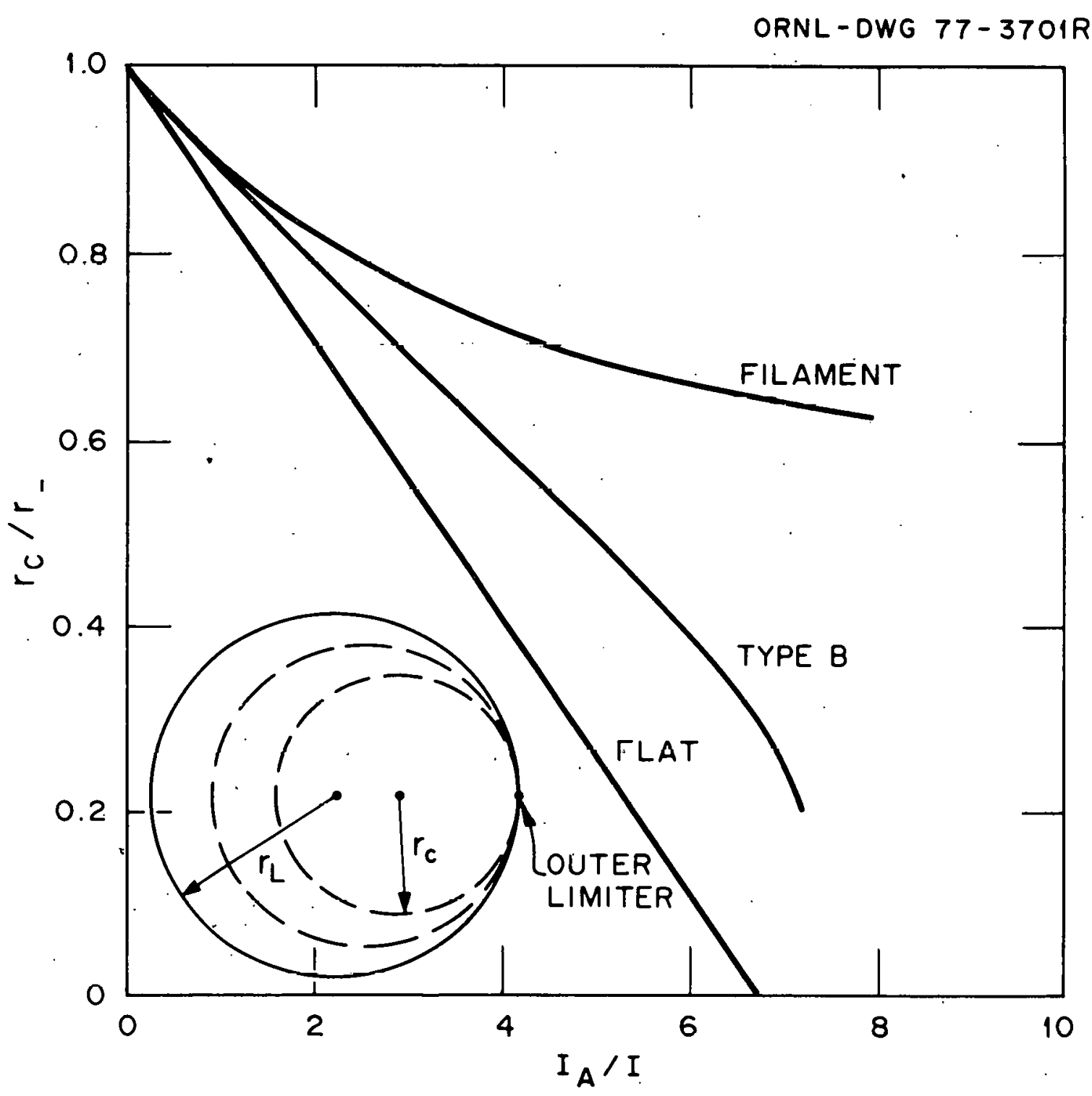

Fig. 2. 


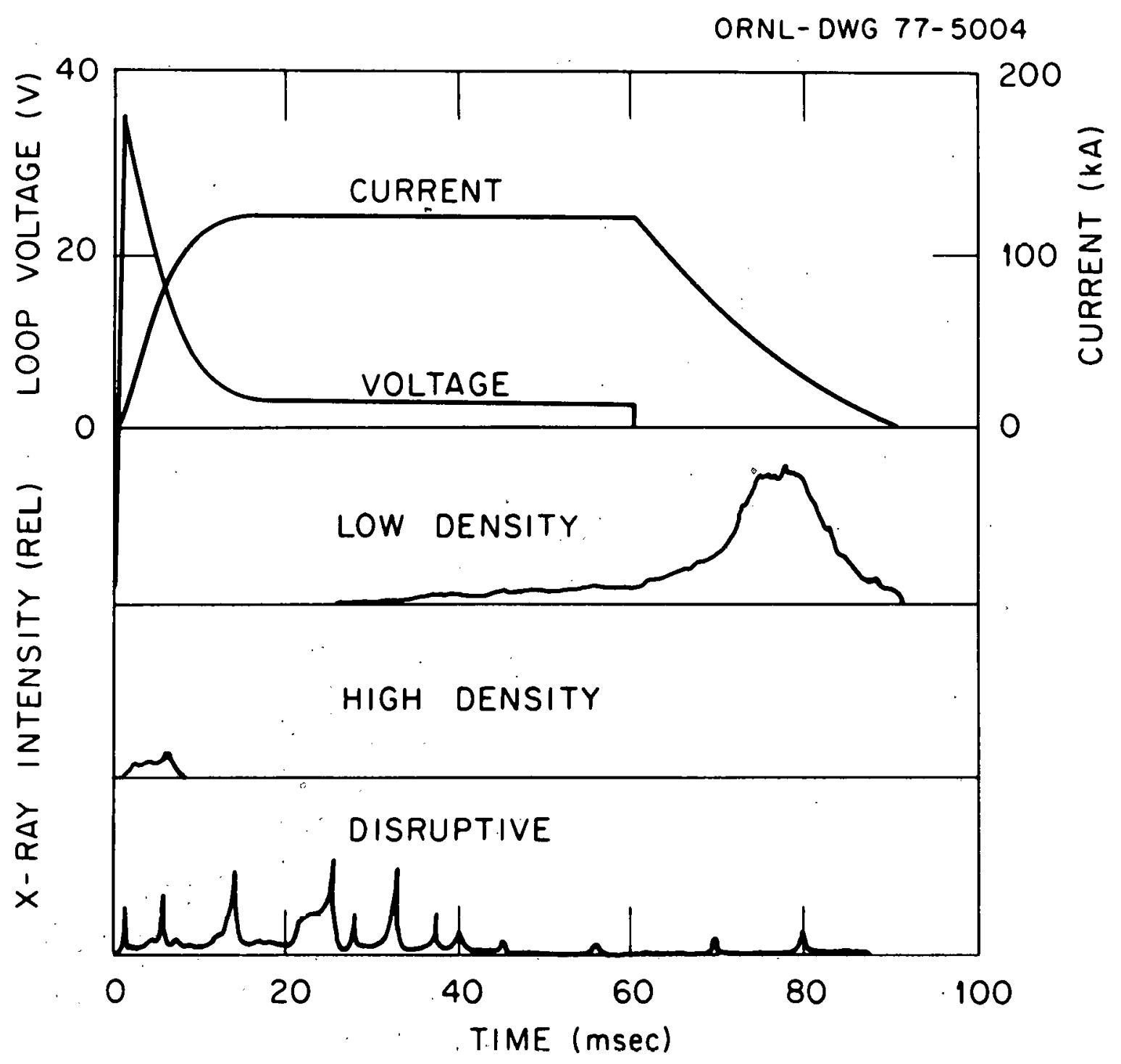

Fig. 3. 


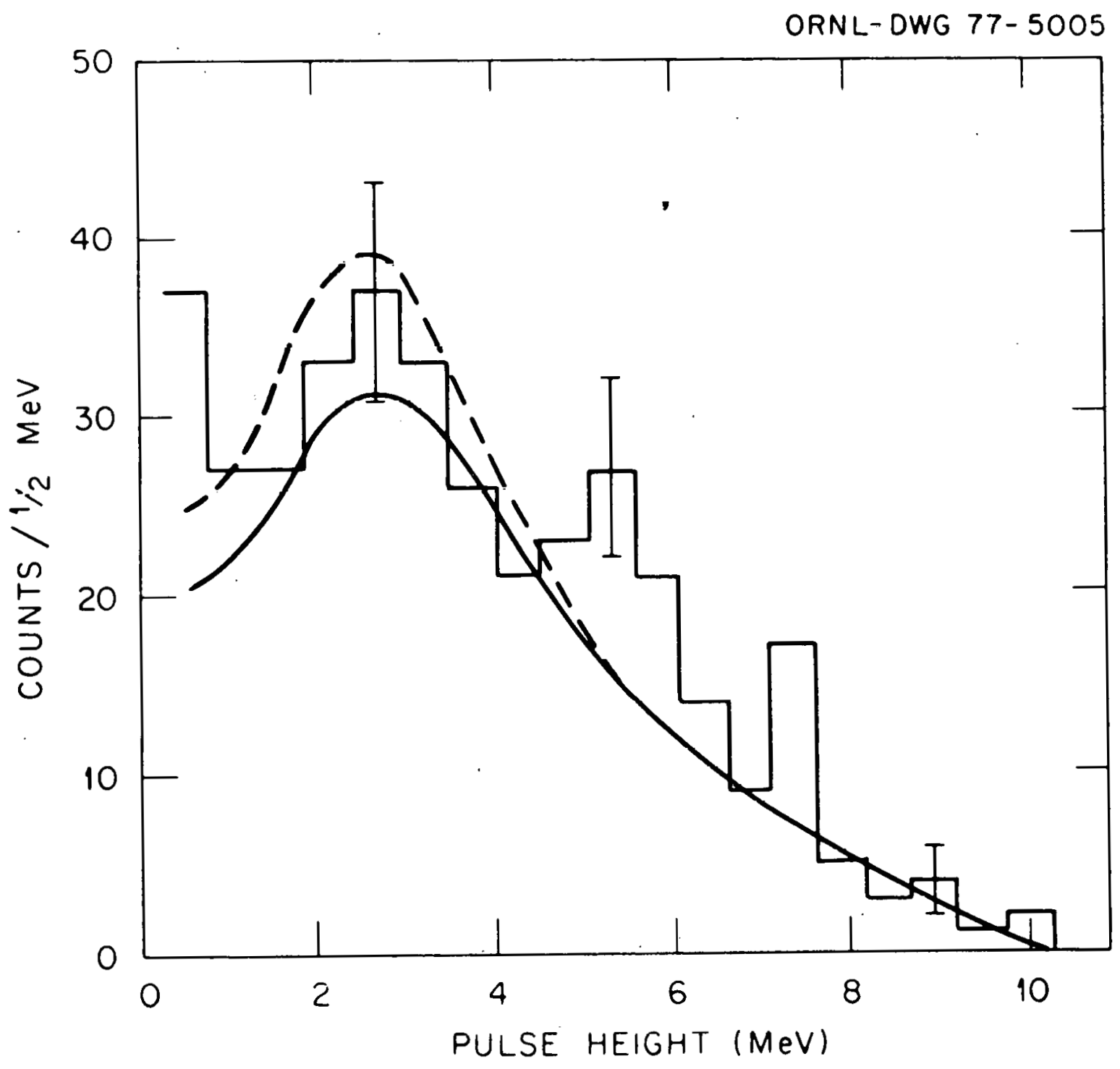

Fig. 4. 

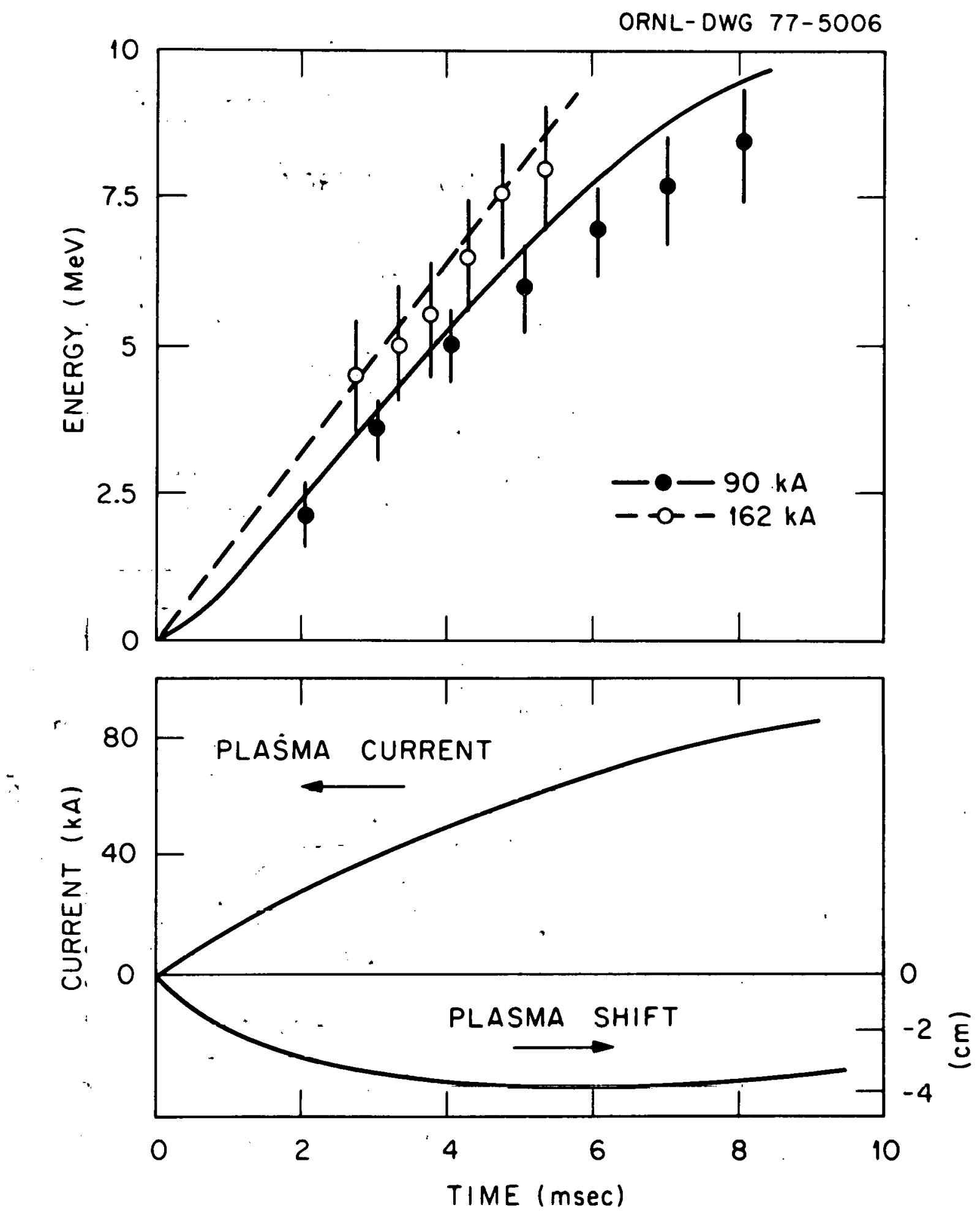

Fig. 5. 


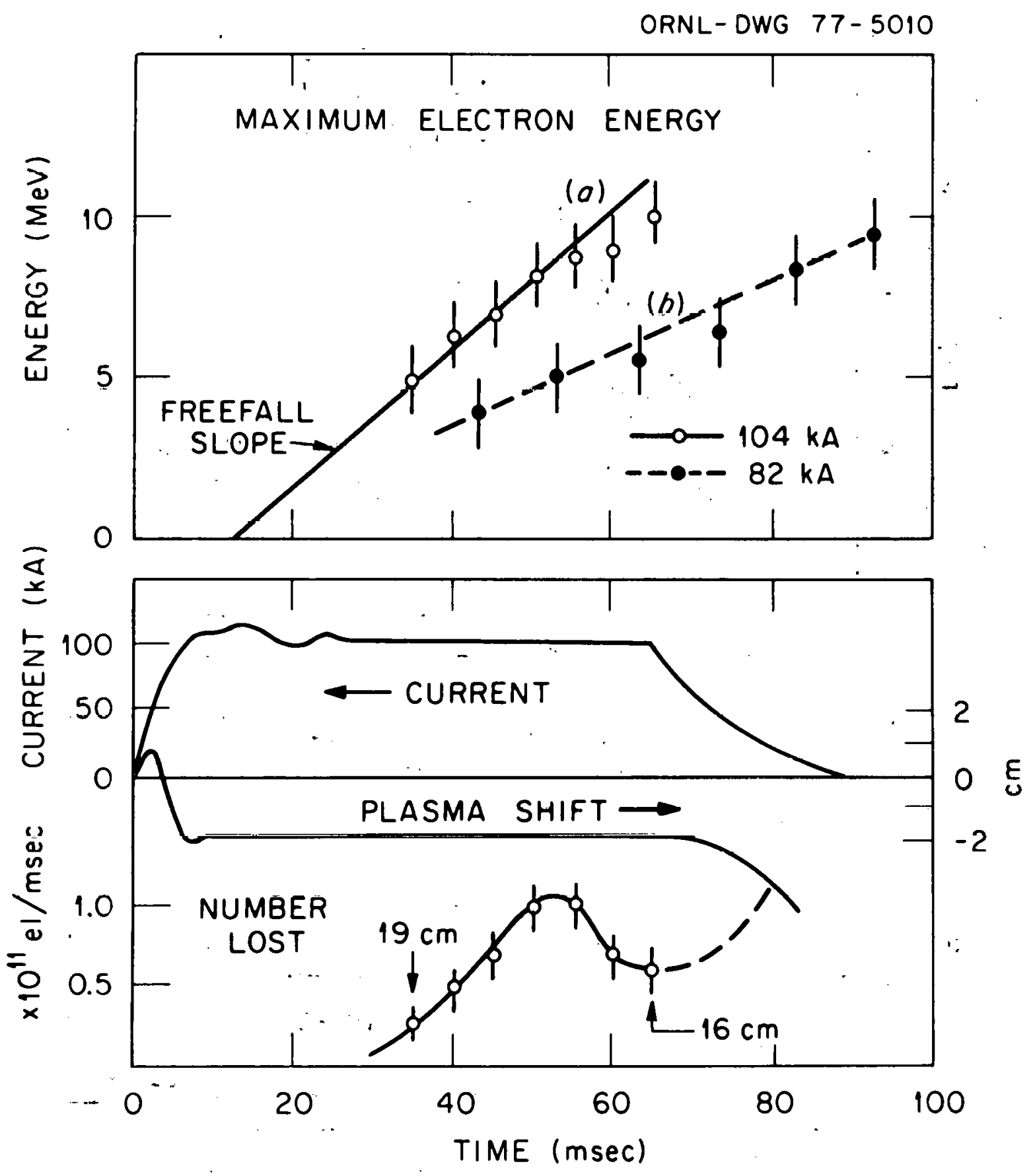

Fig. 6. 

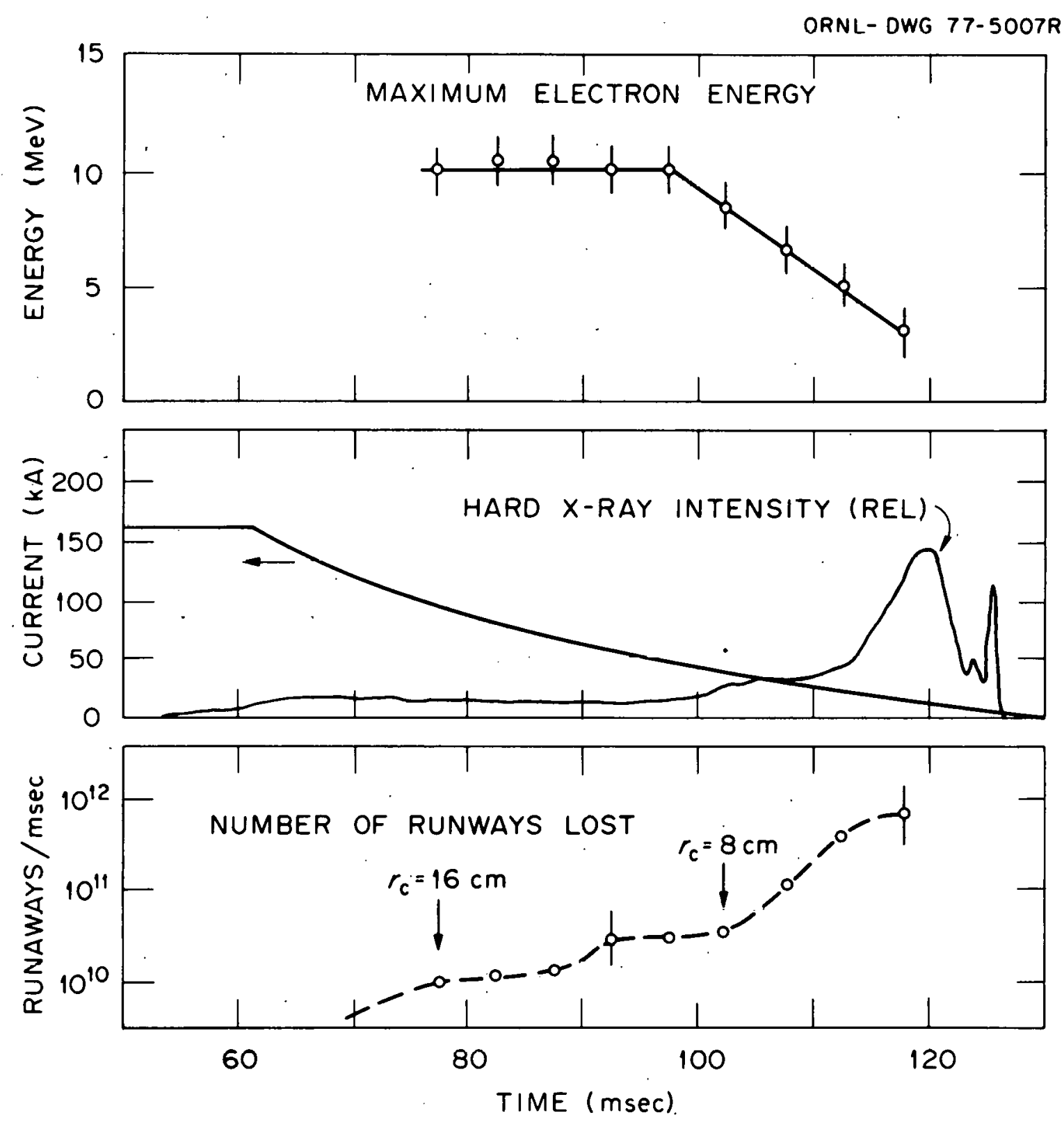

Fig. 7. 


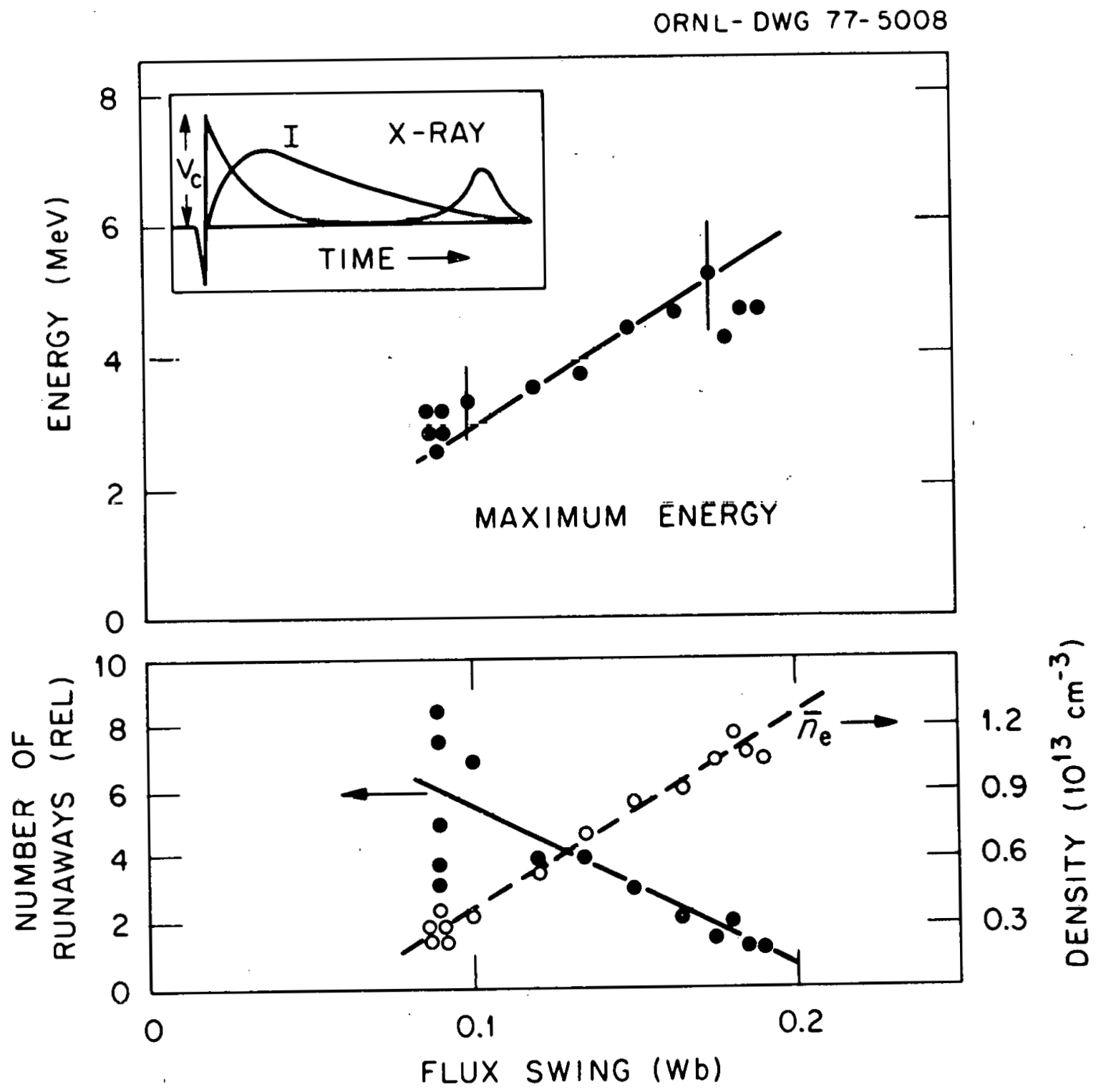

Fig. 8 . 
ORNL- DWG 77-5012

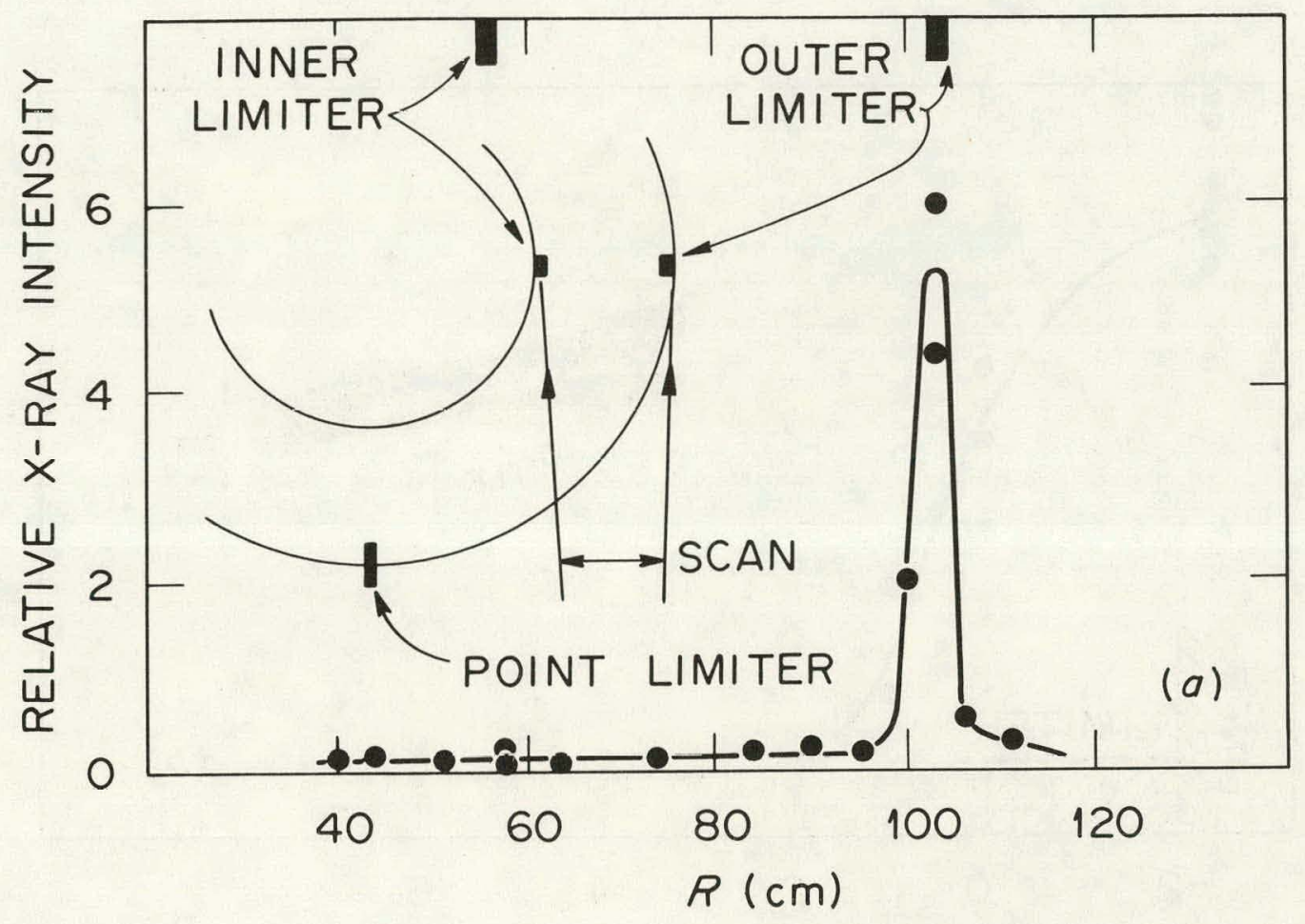

Fig. 9a. 
ORNL-DWG 77-5012

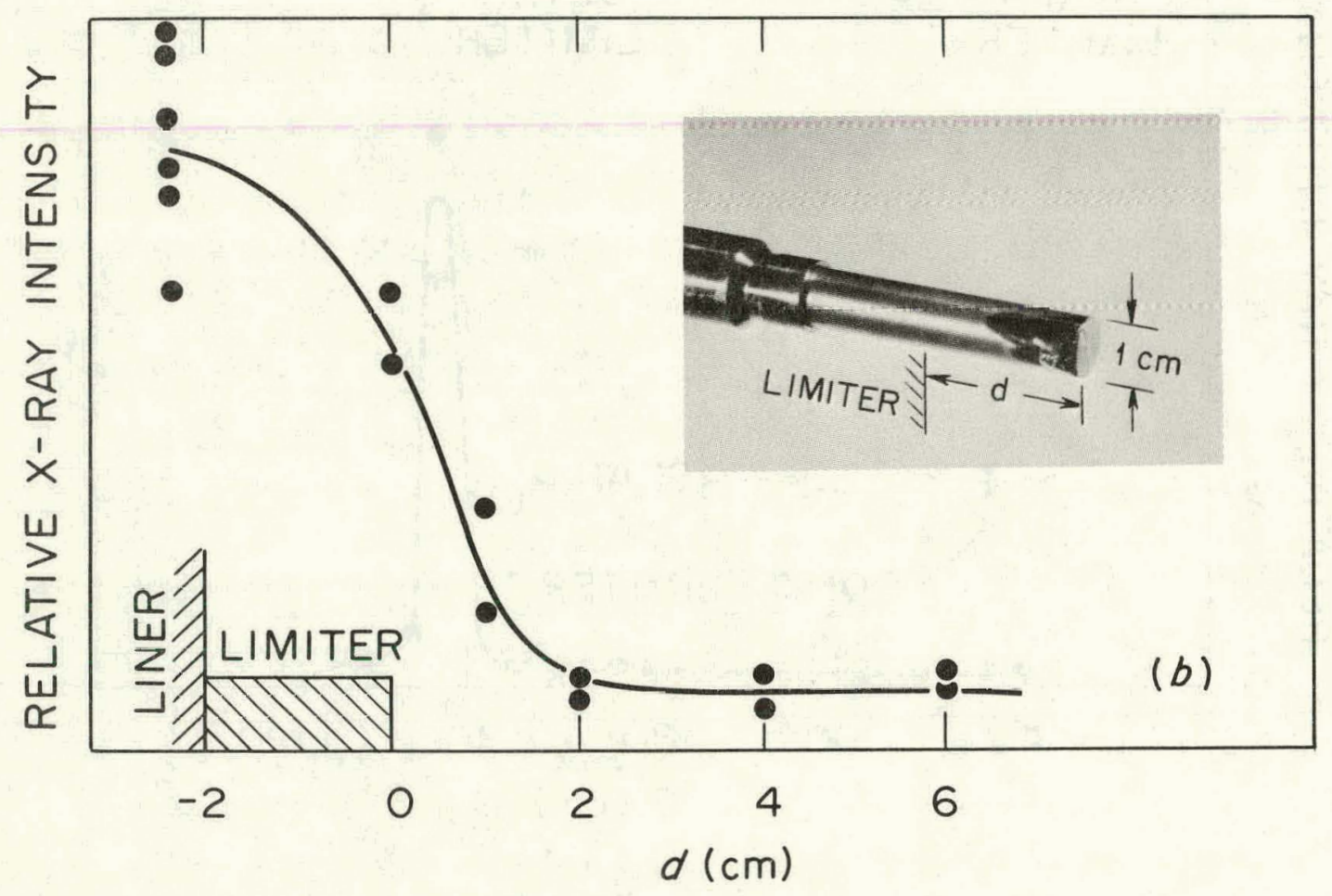

Fig. 9b. 
ORNL- DWG 77-5009

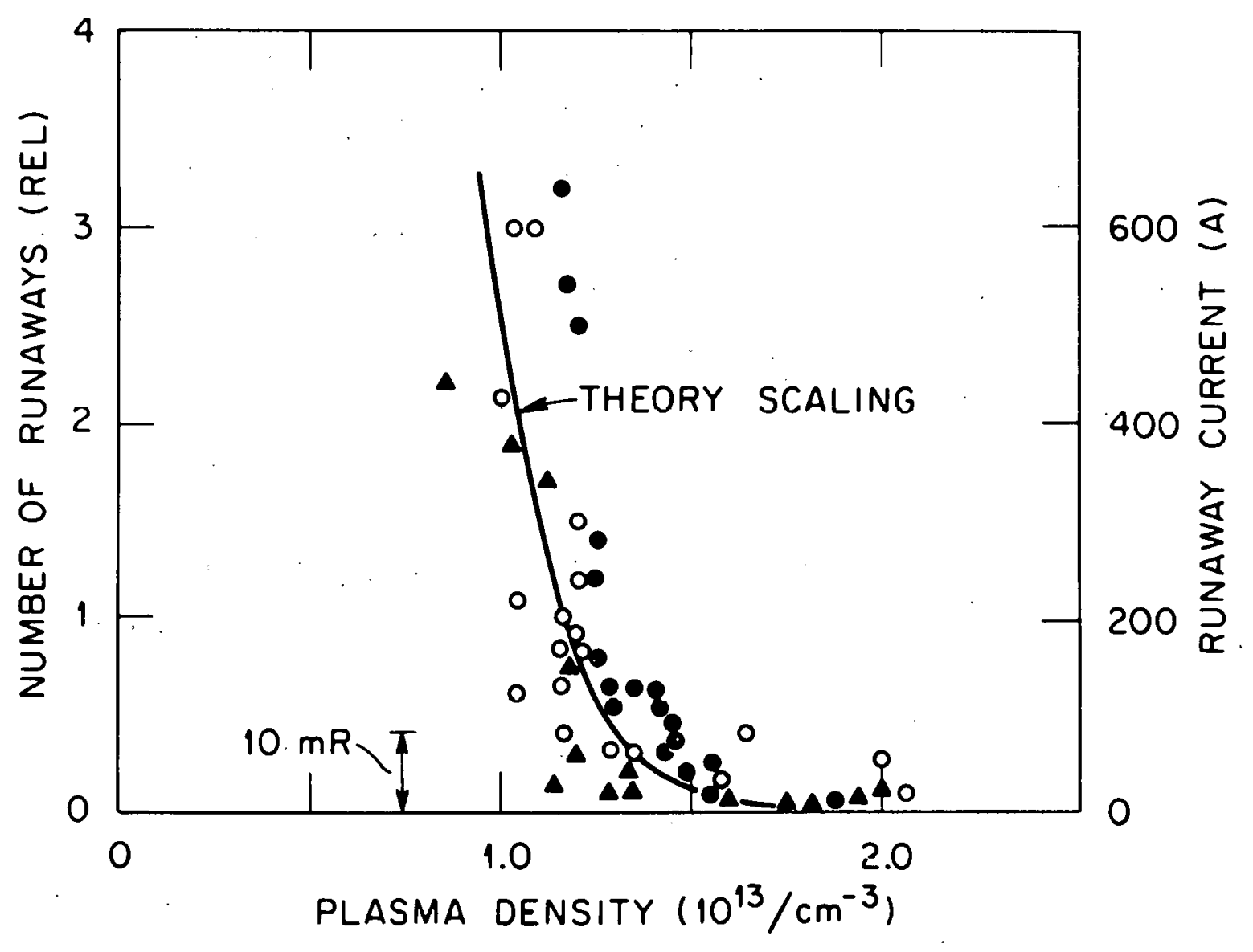

Fig. 10 . 


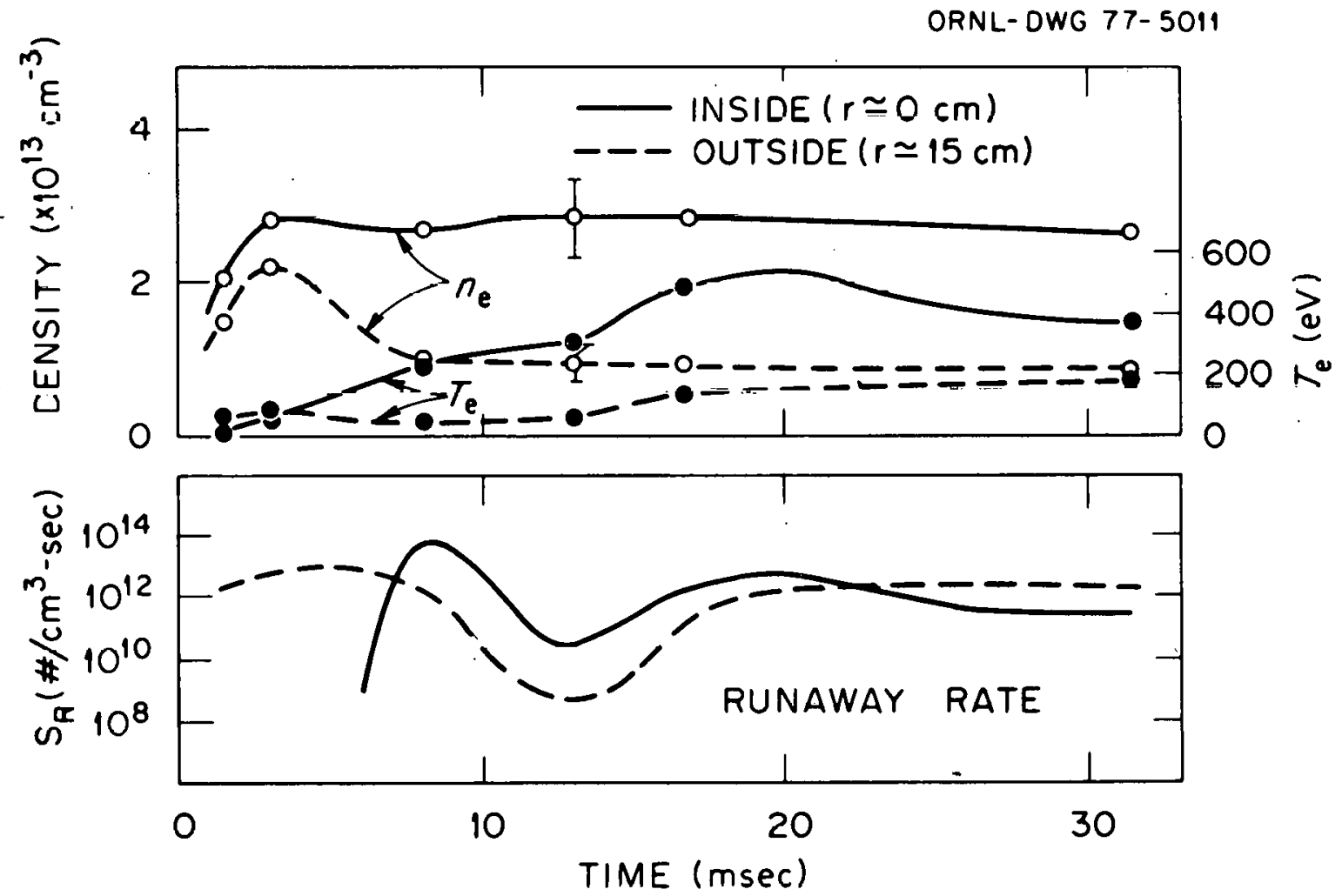

Fig. 11. 
ORNL/TM-6103

\section{INTERNAL DISTRIBUTION}

1. I. A. Berry
2. C. E. Bush
3. J. D. Callen
4. R. J. Colchin
5. A. C. Cooper
6. L. Drooks
7. J. L. Dunlap
8. P. H. Edmonds
9. A. C. England
10. J. T. Hogan
11. H. C. Howe, Jr.
12. R. C. Isler
13. T. C. Jernigan
14. G. G. Kelley
15. H. E. Ketterer
16. P. W. King
17. R. Langley
18. J. F. Lyon
19. D. McNeil1
20. J. T. Mihalczo

21. M. Murakami

22. W. Namkung

23. R. V. Neidigh

24. G. H. Neilson

25. V. K. Paré

26. J. A. Rome

27. D. A. Spong

28. D. W. Swain

29. B. V. Wadde11

30. J. B. Wilgen

31. W. R. Wing

32-33. Centra1 Research Library

34. Document Reference Section

35-36. Laboratory Records Department

37. Laboratory Records, ORNL-RC

38. ORNL Patent office

39. Fusion Energy Division Library

40. Fusion Energy Division Reports Office

\section{EXTERNAL DISTRIBUTION}

41. V. V. Alikaev, Kurchatov Institute of Atomic Energy, 46 Ulitsa Kurchatova, P.0. Box 3402, Moscow, U.S.S.R.

42. J. Bauer, General Atomic Co., P.0. Box 81608, San Diego, CA 92138

43. Bibliothèque, Service du Confinement des Plasmas, C.E.A., B.P. No. 6, 92, Fontenay-aux-Roses (Seine), France

44. Derek Boyd, Department of Physics, University of Maryland, College Park, MD 20742

45. D. Casse1, Mepartment. of Physics, Cornel1 University, Ithaca, NY 14853

46. C. M. Celata, Department of Physics, University of Maryland, College Park, MD 20742

47. Center for Plasma Physics and Thermonuclear Research, University of Texas, Austin, Texas 78712

48. D. Choi, Center for Plasma Physics and Thermonuclear Research, Univereity of Texas, Austin, TX 787.12

49. J. F. Clarke, Division of Magnetic Fusion Energy, Department of Energy, Washingtnn, DC 20545

50. T. Consoli, Centre d'Etudes Nucleaires de Grenoble, Avenue des Martyrs, 38, Grenoble, France

51. Controlled Thermonuclear Research Library, Argonne National Laboratory, 9700 S. Cass Avenue, Argonne, IL 60439

52. Controlled Thermonuclear Research Library, Lawrence Livermore Laboratory, P.0. Box 808, Livermore, CA 94550 
53. CTR Reading, c/o Jay Borris, Plasma Physics Division, Nava1 Naval Research Laboratories, Washington, DC 20390

54. CTR Reading Room, Department of Physics and Astronomy, University of Maryland, College Park, MD 20742

55. CTR Reading Room, c/o B. D. Fried, Physics, Department, University of California, Los Angeles, CA 90024

56. CTR Reading Room, c/o Roy Gould, California Institute of Technology, Pasadena, CA 91103

57. CTR Reading Room, c/o R. Gross, Plasma Research Laboratory, Columbia University, New York, NY 10027

58. CTR Reading Room, c/o T. Kammash, 103 Research Administration Building, North Campus, University of Michigan, Ann Arbor, MI 48105

59. CTR Reading Room, c/o D. W. Kerst, Department of Physics, Sterling Ha11, Univer1sty of Wisconsin, Madison, WI 53706

60. CTR Reading Room, c/o W. B. Thomson, Physics Department, University of California, San nipgn, r.A 92037

61. A. M. Dupas, Documentation S.I.G.N., Department of de la Physique du Plasma, et de la Fusion Controlée, Association Euratom-CEA, B.P. 85, Grenoble, France

62. H. H. Fleischmann, Department of App1ied Physics, Cornell University, Ithaca, NY 14853

63. Gerd Fussman, Max-Planck-Institut für Plasmaphysik, 8046 Garching bei München, Federal Republic of Germany

64. D. Harrill, Department of Physics, Cornell University, Ithaca, NY 14853

65. I. H. Hutchinson, Alcator Group, Francis Bitter National Magnet Laboratory, Massachusetts Institute of Technology, Cambridge, MA 02139

66. H. E. Knoepfel, Laboratorio Gas Ionizzati, C.P. 65, 00044 Frascati (Roma), Italy

67. Librarian, Culham Laboratory, Abingdon, Oxon, OX 14 3DR, England

68. Librarian, Max-Planck-Institut für Plasmaphysik, 8046 Garching bei München, Federal Republic of Germany

69. Library, Centre de Récherches en Physique des Plasmas, 21 Avenue des Bains, 1007 Lausanne, Switzerland

70. Library, FOM-Instituut voor Plasma Fysica, Rijnhuizen, Jutphaas, the Netherlands

71. Library, Laboratorio Gas Ionfzzati, C.P. 65, 00044 Frascati (Roma), Italy

72. C. S. Liu, Department of Physics, University of Maryland, College Park, MD 20742

73. S. Mirnov, Kurchatov Institute of Atomic Energy, 46 Ulitsa Kurchatov, P.0. Box 3402, Moscow, U.S.S.R.

74. G. Mischke, Division of Magnetic Fusion Energy, Mail Code G-234, Department of Energy, Washington, DC 20545

75. K. Molvig, Alcator Group, Francis Bitter National Magnet Laboratory, Massachusetts Institute of Technology, Cambridge, MA 02139

76. J. Norem, Controlled Fusion Division, Argonne National Laboratory, 9700 S. Cass Avenue, Argonne, IL 60439

77. T. Ohkawa, General Atomic Co., P.0. Box 81608, San Deigo, CA 92138 
78. Plasma Physics Group, Department of Engineering Physics, Australian National University, P.0. Box 4, Canberra, A.C.T. 2600, Australia

79. Plasma Physics Library, Princeton Plasma Physics Laboratory, Princeton University, P.0. Box 451, Princeton, NJ 08540

80. Plasma Physics Reading Room, Room 20A-222, Massachusetts Institute of Technology, Cambridge, MA 02139

81. Q Division Library, c/o F. L. Ribe, Los Alamos Scientific Laboratory, P.0. Box 1663, Los Alamos, NM 87544

82. M. S. Rabinovich, Lebedev Institute of Physics, Academy of Sciences of the U.S.S.R., Leninsky Prospect 53, Moscow, U.S.S.R.

83. Research Information Center, Institute of Plasma Physics, Nagoya University, Nagoya, Japan

84. F. Stauffer, Department of Physics, University of Maryland, College Park, MD 20742

85. J. D. Strachan, Princeton Plasma Physics Laboratory, Princeton University, P.0. Box 451, Princeton, NJ 08540

86. Thermonuclear Laboratory, Kurchatov Institute of Atomic Energy, 46 Ulitsa Kurchatova, P.0. Box 3402, Moscow, U.S.S.R.

87. Thermonuclear Library, Japan Atomic Energy Research Institute, Tokai, Naka, Ibaraki, Japan

88. Versator Group, $c / o, G$. Bekef 1 , Department of Physics, Massachusetts Institute of Technology, Cambridge, MA 02139

89. S. von Goeler, Princeton Plasma Physics Laboratory, Princeton University, P.0. Box 451, Princeton, NJ 08540

90. J. Wilkins, Department of Physics, Cornell University, Ithaca, NY 14853

91-99. S. J. Zweben, c/o Department of Physics, University of California, Los Angeles, CA 90024

100. Director, Research and Technical Support Division, DOE-ORO, P.0. Box E, Oak Ridge, TN 37830

101-127. Technical Information Center, P.0. Box 62, Oak Ridge, 'IN 37830 